\title{
Abnormal autonomic modulation of QT interval in patients with idiopathic ventricular tachycardia associated with clinically normal hearts
}

\author{
Lü Fei, Jaswinder S Gill, Demosthenes Katritsis, A John Camm
}

\begin{abstract}
Background-Idiopathic ventricular tachycardia (VT) occurs in a small but important subset of patients without clinically overt heart disease. The mechanism of the arrhythmogenesis remains unclear in these patients. This study examines modulation of the QT interval by the autonomic nervous system in a group of patients with idiopathic ventricular tachycardia.
\end{abstract}

Methods-Cardiac autonomic activity and ventricular repolarisation were studied in 27 patients with VT associated with a clinically normal heart (NHVT) and in 20 normal subjects. All the patients were in sinus rhythm, had normal atrioventricular conduction, and were in a drug free state. Cardiac efferent autonomic activity was measured by spectral analysis of heart rate variability from 24 hour ambulatory electrocardiograms on a Holter analysis system (Marquette). Ventricular repolarisation was evaluated by measuring the QT intervals from the same 24 hour Holter tapes at one hour intervals.

Results-There was no difference in any of the $Q T$ interval variables including the maximum, minimum, and mean of both the QT interval and its corrected value (Bazett's formula) between patients with NHVT and normal subjects. The high frequency component $(0.04-0.15 \mathrm{~Hz})$ of heart rate variability was significantly decreased in patients with NHVT compared with normal subjects (16 (8) $v 21$ (12) ms, p < 0.05). There was a significant correlation between the spectral variables of heart rate variability and the mean, maximal, and minimal QT intervals in normal subjects, whereas the relation was lost in patients with NHVT. No difference was found in mean heart rate between normal subjects and patients with NHVT (70 (9) $v 72$ (13) beats/min, NS).

Conclusions-The high frequency component of heart rate variability is significantly decreased and the relation of QT interval to heart rate variability is significantly altered in patients with NHVT as compared with normal subjects. These findings suggest that abnormal modulation of the QT interval by the autonomic nervous system may play an important part in the arrhythmogenesis of NHVT. This might result from impaired vagal efferent cardiac activity in these patients.

(Br Heart f 1993;69:311-314)

Idiopathic ventricular tachycardia (VT) occurs in a small but important subset of patients with a clinically normal heart (NHVT). ${ }^{12}$ Conditions considered possible as a cause of this arrhythmia include undiagnosed coronary artery disease, unrecognised cardiomyopathy, subclinical myocarditis, localised myocardial disease, and mild mitral valve prolapse. ${ }^{1}$ The significance of these abnormalities in the genesis of the arrhythmia is uncertain, ${ }^{1}$ and the mechanism of arrhythmogenesis in NHVT remains unclear. ${ }^{12}$

Normal and abnormal heart rhythms are subject to the influences of the autonomic nervous system. ${ }^{3}$ Alteration of ventricular repolarisation also plays an important part in both arrhythmogenic and antiarrhythmic mechanisms. There is evidence for an imbalance of cardiac autonomic activity in patients with NHVT. ${ }^{4}$ Perhaps abnormal autonomic activity results in inappropriate modulation of ventricular repolarisation and thus a predisposition to arrhythmia in these patients. To examine this hypothesis, autonomic activity and ventricular repolarisation were studied in 27 patients with NHVT and in 20 normal subjects. Cardiac efferent autonomic activity was measured by spectral analysis of heart rate variability from 24 hour Holter tapes, and ventricular repolarisation was evaluated by measuring QT intervals from the same 24 hour Holter tapes at one hour intervals.

\section{Patients and methods}

PATIENTS

Group I (control group) consisted of 20 clinically normal subjects (10 men and 10 women), mean (SD) age 39 (13) (range 16-68) years. None had appreciable cardiac or other medical problems and their 24 hour ambulatory electrocardiograms were all normal and without evidence of arrhythmia.

Group II consisted of 27 patients (15 men and 12 women) with NHVT, aged 39 (14) (range 16-72) years. There were no significant differences in age and sex between groups I and II. None of these patients had a history of heart disease.

All patients had a normal clinical examination, normal chest radiography, and normal resting electrocardiograms. Patients with 
autonomic neuropathy, atrial fibrillation, sinus node dysfunction, a cardiac pacemaker, or intraventricular conduction delay were excluded. No patient had angiographic evidence of coronary artery disease, reduced left ventricular ejection fraction, or regional wall motion abnormality during left ventricular cineangiography as assessed by two independent observers. The VT was non-sustained in 12 patients (group $\mathrm{II}_{\mathrm{a}}$ ) and sustained in the other 15 (group $\mathrm{II}_{\mathrm{b}}$ ). Non-sustained VT was defined as broad QRS complexes that occur at a rate of more than 120 beats $/ \mathrm{min}$, last more than three beats but less than $30 \mathrm{~s}$, and end spontaneously without haemodynamic compromise. Sustained VT was defined as QRS complexes that occur at a rate of more than 120 beats/min, last more than $30 \mathrm{~s}$, or require intervention to end them because of haemodynamic instability.

Cardiac biopsy specimens showed normal histology in all but four patients in whom mild non-specific fibrosis was found.

ANALYSIS OF HEART RATE VARIABILITY

All subjects underwent two channel (modified $V_{5}$ and $V_{1}$ leads) 24 hour ambulatory electrocardiographic monitoring in a drug free state. All patients were in sinus rhythm and had normal atrioventricular conduction. Heart rate variability was analysed from the 24 hour ambulatory electrocardiogram with a Holter analysis system (Marquette Series 8000). After classification of the QRS morphology, the longest and the shortest $R R$ intervals on the $R R$ interval histogram were manually confirmed until no QRS complex was mislabelled as either an artifact or a supraventricular ectopic beat. The largest and the smallest $R R$ ratios on the $R R$ ratio histogram were also visually checked to ensure all normal and abnormal QRS complexes on the ambulatory electrocardiograms were correctly labelled. When calculating the heart rate variability measurements, we used only normal to normal intervals. Each interval that was to be excluded due to ectopic beats or artifacts was replaced by holding the previous coupling interval level throughout the time interval to the next valid coupling interval. The beat to beat fluctuations were converted to frequency domain by the fast Fourier transformation and the spectral measures were computed as the square root of areas under the power spectrum. In this study, heart rate variability was expressed as total $(0.01-1.00 \mathrm{~Hz})$, low $(0.04-0.15 \mathrm{~Hz})$, and high $(0 \cdot 15-0 \cdot 40 \mathrm{~Hz})$ frequency components. Mean heart rate was also calculated from the 24 hour Holter tapes.

MEASUREMENTS OF THE QT INTERVAL

On each patient the QT interval was measured from electrocardiographic strips that were selected from 24 hour Holter tapes at one hour intervals. The electrocardiograms were then enlarged $\times 2$ by photocopying. The enlarging precision of the photocopier was confirmed by the calibration signal on the electrocardiograms. The QRST complex chosen for measurement of the QT interval was at least three normal beats after, and not preceding any ventricular ectopic beats.

The QT interval was defined as the interval between the onset of the QRS complex and the end of the $T$ wave. The end of the $T$ wave was defined as the intersection point of the isoelectric line and the tangent line of the maximal downslope of the $\mathrm{T}$ wave. ${ }^{5}$ All QT intervals were measured on channel one (the modified $V_{5}$ lead) as the $T$ wave on channel two was sometimes of low amplitude and difficult to measure accurately. Three values of the QT interval were measured in each subject. Mean, minimal, and maximal QT intervals were the mean, the shortest, and the longest values of the $24 \mathrm{QT}$ intervals measured throughout the 24 hour period at one hour intervals.

\section{STATISTICAL ANALYSIS}

Unpaired Student's $t$ test, $\chi^{2}$ test, and multiple variance correlation and regression were used as appropriate. Analysis of covariance (with age as a covariate) was used for comparing the heart rate variability measurements to adjust for the influence of age. ${ }^{67}$ The differences in the slopes of regression lines were tested by the method of Armitage and Berry. All data were expressed as mean (SD). A p value of $<0.05$ was considered statistically significant.

\section{Results}

There was no difference in mean heart rate between groups I and II (70 (9) $v 72$ (13) beats/min, NS).

\section{HEART RATE VARIABILITY}

Table 1 shows that there were no significant differences in the low and total frequency components of heart rate variability between group I and group II. The high frequency component of heart rate variability was, however, significantly lower in group II than in group I (16 (8) $v 21$ (12) $\mathrm{ms}, \mathrm{p}<0.05)$ There was also no difference in any of the three frequency components of heart rate variability between groups $\mathrm{II}_{\mathrm{a}}$ and $\mathrm{II}_{\mathrm{b}}$.

QT INTERVAL

Table 2 shows QT intervals expressed as both absolute and corrected values including the mean (SD), maximal and minimal values, and their differences. The corrected QT

Table 1 Heart rate variability and mean heart rate in patients with NHVT and normal subjects

\begin{tabular}{|c|c|c|c|c|}
\hline Groups & $I$ & $I I$ & $I I_{a}$ & $I I_{b}$ \\
\hline No & 20 & 27 & 12 & 15 \\
\hline $\begin{array}{l}\text { Mean heart rate } \\
\text { (beats } / \mathrm{min} \text { ) }\end{array}$ & $70(9)$ & 72 (13) & $78(10)$ & $69(14)$ \\
\hline $\begin{array}{l}\text { Heart rate variability con } \\
\text { Total frequency (ms) } \\
\text { Low frequency (ms) } \\
\text { High frequency (ms) }\end{array}$ & $\begin{array}{l}\text { mponents: } \\
55(22) \\
36(15) \\
21(12)\end{array}$ & $\begin{array}{l}47(19) \\
32(14) \\
16(8)^{\star}\end{array}$ & $\begin{array}{l}42(19) \\
28(15) \\
14(8)\end{array}$ & $\begin{array}{l}52(19) \\
35(14) \\
17(8)\end{array}$ \\
\hline
\end{tabular}

${ }^{\star} \mathrm{p}<0.05$. Values are expressed as mean $(\mathrm{SD})$ 
Table $2 Q T$ intervals (mean (SD) seconds) in patient with NHVT and normal subjects

\begin{tabular}{lllll}
\hline Groups & $I$ & $I I$ & $I I_{\lrcorner}$ & $I I_{b}$ \\
\hline Absolute values: & & & & \\
$\quad$ Mean & $0.37(0.03)$ & $0.37(0.10)$ & $0.38(0.06)$ & $0.35(0.10)$ \\
SD & $0.03(0.01)$ & $0.03(0.01)$ & $0.03(0.01)$ & $0.03(0.01)$ \\
Maximum & $0.42(0.05)$ & $0.42(0.05)$ & $0.43(0.06)$ & $0.42(0.04)$ \\
Minimum & $0.33(0.03)$ & $0.33(0.04)$ & $0.33(0.04)$ & $0.32(0.04)$ \\
$\quad$ Ranget & $0.09(0.03)$ & $0.10(0.03)$ & $0.10(0.03)$ & $0.10(0.03)$ \\
Corrected values: & & & & \\
$\quad$ Mean & $0.42(0.02)$ & $0.42(0.02)$ & $0.43(0.03)$ & $0.42(0.02)$ \\
SD & $0.04(0.06)$ & $0.02(0.01)$ & $0.03(0.01)$ & $0.02(0.01)$ \\
Maximum & $0.47(0.04)$ & $0.47(0.04)$ & $0.49(0.03)$ & $0.45(0.03)$ \\
Minimum & $0.37(0.02)$ & $0.38(0.03)$ & $0.38(0.04)$ & $0.38(0.03)$ \\
Ranget & $0.10(0.03)$ & $0.10(0.08)$ & $0.11(0.04)$ & $0.10(0.10)$ \\
\hline
\end{tabular}

* Standard deviation about the mean of hourly QT interval over 24 hours.

†Difference between the maximum and the minimum of QT intervals.

interval $\left(\mathrm{QT}_{\mathrm{c}}\right)$ was calculated by dividing the measured QT interval by the square root of the preceding $R R$ interval using Bazett's formula $\left(Q_{c}=Q T / \sqrt{R R}\right.$, in seconds). None of the QT intervals and their corrected values differed significantly between group I and group II nor between group $\mathrm{II}_{\mathrm{a}}$ and group.

\section{CORRELATIONS BETWEEN QT INTERVALS AND} HEART RATE VARIABILITY

There was a statistically significant correlation between the spectral values of heart rate variability and the mean, maximal, and minimal values of QT intervals in group I, whereas this relation was not found in group II (table 3). The slope of the regression lines between the minimal QT interval and the high frequency component of heart rate variability was significantly altered $(-1.2536 v$ $1.6313, \mathrm{p}<0.01)$ in patients with NHVT compared with normal subjects (fig).

\section{Discussion}

Idiopathic VT occurs in a small but important subset of patients without overt heart disease. ${ }^{12}$ Most of these patients have a good prognosis, ${ }^{9}$ but sudden cardiac death may occur. ${ }^{10}$ Although there have been many reports concerning NHVT, ${ }^{1}$ its mechanism remains uncertain ${ }^{12}$ and the condition has been considered as a primary electrical disease. $^{1}$

Heart rate variability has been used as a measure of the effect of the autonomic nervous system on the integrity of cardiovascular activity in many clinical entities including sudden cardiac death ${ }^{11}$ and cardiac arrhythmias. ${ }^{1213}$ Decreased heart rate variability has

Table 3 Correlation coefficients between $Q T$ intervals and spectral heart rate variability

\begin{tabular}{lccc}
\hline & \multicolumn{2}{c}{ Frequency components of heart rate variability } \\
\cline { 2 - 4 }$Q T$ intervals & Total & Low & High \\
\hline Mean: & & $0.56^{\star \star}$ & $0.58^{\star \star}$ \\
Group I & $0.60^{\star \star}$ & -0.11 & -0.13 \\
Group II & -0.09 & & \\
Maximum: & & $0.59^{\star \star}$ & $0.57^{\star \star}$ \\
Group I & $0.61^{\star \star}$ & -0.01 & 0.05 \\
Group II & 0.02 & & \\
Minimum: & & $0.60^{\star \star \star}$ & $0.71^{\star \star}$ \\
Group I & $0.67^{\star \star \star}$ & -0.27 & -0.28 \\
Group II & -0.23 & &
\end{tabular}

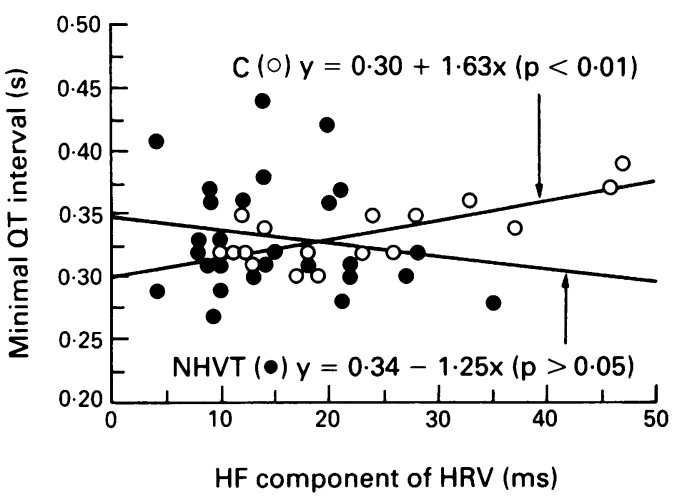

Regression lines between the high frequency (HF) component of heart rate variability (HRV) and minimal $Q T$ interval in patients with ventricular tachycardia associated with clinically normal hearts (NHVT) and in controls $(C)$. The slopes are significantly different $(p<0.01)$.

been shown to exist in patients with chronic heart failure ${ }^{8}$ and to correlate with an increased mortality in patients recovering from myocardial infarction. ${ }^{14}$ It has been assumed that the low frequency component of heart rate variability in the frequency domain provides a measure of predominantly sympathetic activity with some influence from vagal activity, whereas the high frequency component relates almost exclusively to vagal modulation. ${ }^{15-18}$

Our results showed that the high frequency component of heart rate variability was significantly decreased in patients with NHVT, suggesting impaired cardiac efferent vagal activity. We have previously shown an impaired sympathovagal balance in a smaller number of patients with NHVT from the same group examined in the present study. ${ }^{4}$ Heart rate variability has been reported by several authors to decrease with age in normal subjects. ${ }^{67}$ The differences in heart rate variability in our study, however, were not attributable to difference in age as analysis of covariance was applied to adjust for the influence of age on heart rate variability. Also, the difference in age was not statistically significant between the groups that have been compared. The role of sympathetic activity in the genesis of arrhythmias has been well studied, ${ }^{19} 20$ but the relation of vagal activity to arrhythmogenesis remains to be fully elucidated. Previous reports suggest that sympathetic activation can trigger malignant arrhythmias, whereas vagal activation may exert a protective effect. ${ }^{21-24}$ Our results indicate that reduced vagal activity may also play an important part in arrhythmogenesis in patients with NHVT.

A prolonged QT interval is associated with an increased risk of sudden cardiac death. ${ }^{25}$ Ventricular repolarisation is predominantly under $\beta$ adrenergic control ${ }^{26}$ and sympathetic stimulation shortens the QT interval. ${ }^{2728}$ There is evidence of vagal innervation of the ventricle $^{29}$ and that vagus may also be directly involved in the modulation of the QT interval. $^{30-32}$ There is also evidence that the vagus nerve exerts its effect on the electrophysio- 
logical properties of the ventricular myocardium by modifying the effect of sympathetic activity on the normal ventricle. ${ }^{23}{ }^{33}$ The interaction of the two opposing branches of the autonomic nervous system may play a more important part than either one alone in the pathophysiological activities of the heart. ${ }^{34} 35$ Decreased vagal activity may have similar effects on the dispersion of refractoriness as does increased sympathetic activity in the genesis of arrhythmias. In our study, no differences were found in the QT intervals and their corrected values, or mean heart rates between groups I and II, or between groups $\mathrm{II}_{\mathrm{a}}$ and $\mathrm{II}_{\mathrm{b}}$. The relation between measures of the QT interval and heart rate variability was significantly altered, however, in patients with NHVT compared with normal subjects (table 3 and fig). Inappropriate modulation of the QT interval by abnormal autonomic activity, which is probably due to impaired vagal activity, might be the explanation for the primary electrical disturbance in patients with NHVT.

One limitation is that the QT interval was measured at one hour intervals instead of on a beat to beat basis. This may reduce the sensitivity and hence the ability to detect an alteration of the QT interval in relation to autonomic tone. In our study, the lack of a relation between QT interval and heart rate variability in patients with NHVT was unlikely to be due to this limitation as there was a statistically significant relation between QT interval and heart rate variability in a smaller number of normal subjects.

We conclude that the high frequency component of heart rate variability is significantly decreased and the relation of the QT interval to heart rate variability is significantly altered in patients with NHVT as compared with normal subjects. These findings suggest that in patients with NHVT abnormal modulation of the QT interval by the autonomic nervous system may play an important part in the arrhythmogenesis, which is probably due to impaired vagal cardiac activity.

We are indebted to Sister S Bent and Drs F Murgatroyd and I Sneddon for their help in collecting the clinical data and to Dr J Poloniecki for his advice on the statistical analysis of the data.

1 Brooks R, Burgess JH. Idiopathic ventricular tachycardia Medicine-Baltimore 1988;67:271-94.

2 Rodriguez LM, Waleffe A, Brugada P, Dehareng A Lezaun R, Sternick EB, Kulbertus HE. Exercisenduced sustained symptomatic ventricular tachycardia: incidence, clinical, angiographic and electrophysiologic characteristics. Eur Heart $f$ 1990;11:225-32.

3 Coumel P, Leenhardt A. Mental activity, adrenergic modulation, and cardiac arrhythmias in patients with heart disease. Circulation 1991;83 (suppl 4):58-70

4 Gill JS, Lü F, Paul V, Ward DE, Camm AJ. Evidence of autonomic imbalance from analysis of heart rate variability in patients with and without exercise-induced ventricular tachycardia in clinically normal heart ventricular tachycardia in
[abstract]. PACE 1991;14:707.

5 Browne KF, Prystowsky E, Heger JJ, Zipes DP. Modulation of the QT intervals by the autonomic nerModulation of the QT intervals by
vous system. PACE 1983;6:1050-6.

6 Brüggemann T, Andersen D, Völler H, Schröder R. Heart rate variability from Holter monitoring in a normal population [abstract]. Circulation 1990;84(suppl):595.
7 Saul JP, Arai Y, Berger RD, Lilly LS, Colucci WS, Cohen RJ. Assessment of autonomic regulation in chronic congestive heart failure by heart rate spectral analysis. $A m \mathcal{F}$ Cardiol 1988;61:1292-9.

8 Armitage P, Berry G. Statistical methods in medical research. Oxford: Blackwell Sci Publications, 1987, 273-82.

9 Horowitz LN. Ventricular arrhythmias: control of therapy by Holter monitoring. Eur Heart $\mathcal{f}$ 1989;10(suppl E):53-60

10 Wellens HJ, Lemery R, Smeets JL, Brugada P, Gorgels AP, Cheriex EC, de Zwaan C. Sudden arrhythmic death without overt heart disease. Circulation 1992;85(suppl I):92-7.

11 Martin GJ, Magid NM, Myers G, Barnett PS, Schaad JW, Weiss JS, et al. Heart rate variability and sudden death secondary to coronary artery disease during ambulatory electrocardiographic monitoring. $\mathrm{Am} f$ Cardiol 1987;60:86-9.

12 Coumel P. Modifications of heart rate variability preceding the onset of tachyarrhythmias. Cardiologia 1990;35(suppl 1):7-12.

13 Billman GE, Hoskins RS. Time-series analysis of heart rate variability during submaximal exercise. Evidence for reduced cardiac vagal tone in animals susceptible to ventricular fibrillation. Circulation 1989;80:146-57.

14 Cripps TR, Camm AJ. Prediction of arrhythmic events in patients following myocardial infarction. Clin Cardiol 1989;12:661-5.

15 Huikuri HV, Kessler KM, Terracall E, Castellanos A, Linnaluoto MK, Myerburg RJ. Reproducibility and circadian rhythm of heart rate variability in healthy subjects. Am ₹ Cardiol 1990;65:391-3.

16 Pomeranz B, Macaulay RJ, Caudill MA, Kutz I, Adam D, Gordon D, et al. Assessment of autonomic function in humans by heart rate spectral analysis. Am $\mathcal{F}$ Physiol 1985;248:151-3.

17 Akselrod S, Gordon D, Ubel FA, Shannon DC, Barger AC, Cohen RJ. Power spectral analysis of heart rate fluctuation: a quantitative probe of beat-to-beat cardiovascular control. Science 1981;213:220-2.

18 Hayano J, Sakakibara Y, Yamada A, Yamada M, Mukai $\mathrm{S}$, Fujinami T, et al. Accuracy of assessment of cardiac vagal tone by heart rate variability in normal subjects. Am f Cardiol 1991;67:199-204.

19 Meredith IT, Broughton A, Jennings GL, Esler MD. Evidence of a selective increase in cardiac sympathetic activity in patients with sustained ventricular arrhyth mias. N Eng f Med 1991;325:618-24.

20 Podrid PJ, Fuchs T, Candinas R. Role of the sympathetic nervous system in the genesis of ventricular arrhythmia. Circulation 1990;82(suppl 2):103-13.

21 Schwartz PJ, La Rovere MT, Vanoli E. Autonomic nervous system and sudden cardiac death. Experimental basis and clinical observations for post-myocardial infarction risk stratification. Circulation 1992;85:(suppl I):77-91

22 Facchini M, De-Ferrari GM, Bonazzi O, Weiss T, Schwartz PJ. Effect of reflex vagal activation on frequency of ventricular premature complexes. $\mathrm{Am} \mathcal{f}$ Cardio 1991;68:349-54

23 Yoon MS, Han J, Tse WW, Rogers R. Effects of vagal stimulation, atropine, and propranolol on fibrillation threshold of normal and ischemic ventricles. Am Heart $\mathcal{f}$ 1977;93:60-5.

24 Farrel TG, Paul V, Cripps TR, Malik M, Bennett ED, Ward DE, Camm AJ. Baroreflex sensitivity and electrophysiological correlates in patients after acute myocarphysiological correlates in patients after acur

25 Schwartz PJ, Wolf S. QT interval prolongation as predictor of sudden death in patients with myocardial infarction. Circulation 1978;57:1074-7.

26 Surawicz B. The QT interval and cardiac arrhythmias. Annual Review of Medicine 1987;38:81-90.

27 Nattel S, Euler DE, Spear JF, Moore EN. Autonomic control of ventricular refractoriness. Am $\mathcal{J}$ Physiol $\mathrm{N}$ 1981;241:878-82.

28 Martins JB, Zipes DP. Effects of sympathetic and vagal nerves on recovery properties of the endocardium and $\sigma$ epicardium of the canine left ventricle. Circ Res 1980;46:100-10.

29 Takahashi N, Barber MJ, Zipes DP. Efferent vagal innervation of canine ventricle. Am 7 Physiol 1985;248:89-97.

30 Abildskov JA. The prolonged QT interval. Annual Review of Medicine 1979;30:171-9.

31 Browne KF, Zipes DP, Heger JJ, Prystowsky EN. O Influence of the autonomic nervous system on the QT Influence of the autonomic nervous system on the
interval in man. Am 7 Cardiol 1982;50:1099-103.

32 Cappato R, Alboni P, Pedroni P, Gilli G, Antonioli GE. \ֶ Sympathetic and vagal influences on rate-dependent changes of QT interval in healthy subjects. Am J Cardiol 1991;68:1188-93.

33 Fischmeister R, Hartzell HC. Mechanism of action of $\bigcirc$ acetylcholine on calcium current in single cells from frog ventricle. $\mathcal{f}$ Physiol 1986;376:183-202.

34 Zipes DP, Miyazaki T. The autonomic nervous system $\bar{Q}$ and the heart: basis for understanding interactions and $\rightleftharpoons$ effects on arrhythmia development. In: Zipes DP, Jalife J, eds. Cardiac electrophysiology. From cell to bedside. Philadelphia: W B Saunders; 1990:312-30.

35 Verrier RL. Neurogenic aspects of cardiac arrhythmias. In: El-Sherif N, Samet P, eds. Cardiac pacing and electrophysiology. Philadelphia: W B Saunders, 1991:77-91. 